\title{
CRÍTICA LITERARIA Y ESFERA PÚBLICA: EL ENSAYO DE HERNANDO TÉLLEZ (1940-1950)
}

\author{
Alfredo Laverde Ospina
}

El intelectual no es el que piensa sino el que opina Nicolás Gómez Dávila

O ato crítico é a disposição de empenhar a personalidade, por meio da inteligência e da sensibilidade, através da interpretação das obras, vistas sobretudo como mensagem de homem a homem. O ato crítico se beneficia com a sistematização teórica, mas não se confunde com ela, nem substitui o outro. Antonio Candido

\section{DIAGNÓSTICO DE UNA CRISIS}

La retirada de la crítica literaria del ámbito público ha sido atribuida, entre múltiples causas, a la pérdida de relevancia del valor estético en la constitución del canon literario en relación con otros productos discursivos y artefactos culturales, además del alto grado de tecnificación de la que la crítica ha sido objeto al ingresar al ámbito académico. Estas razones, entre otras, han sido esgrimidas como argumentos incontestables ante su creciente marginalidad en la esfera pública y en la constitución de la opinión pública, junto a la determinación de las agendas políticas y culturales.

Guillermo Mariaca Iturri, consciente de este desplazamiento, propone, en El poder de la palabra. Ensayos sobre la modernidad de la crítica cultural hispanoamericana (2007), el trazado de una tradición de la crítica literaria 
continental y subraya el conjunto de aspectos concernientes al lugar ocupado por ella, al menos desde las dos primeras décadas del siglo XX hasta los años ochenta. A este respecto, el autor boliviano sustenta el papel cumplido por la crítica tanto en el ámbito literario como cultural y político:

La crítica literaria hispanoamericana ha organizado su reflexión en torno a tres núcleos epistemológicos que generarían el sentido y que son, al mismo tiempo, condición de su efecto [...] El lenguaje, la cultura y la ideología son las tres claves que recorren todo el trabajo de la crítica. Concebido como trabajo o como celebración, el lenguaje y su importancia como 'materia prima' de la literatura está presente en toda la obra a analizarse; el lenguaje sería el que posibilita la constitución de una tradición literaria y abre la posibilidad de su universalización. La cultura latinoamericana concebida como cultura nacional, recorre los textos centrales en cada una de sus reflexiones construyendo a la literatura como política cultural y enfatizando las encrucijadas de la identidad. Finalmente la ideología, es decir la constitución de sujetos, sean estos escritores o lectores, es también preocupación compartida; nuestra literatura, según afirma nuestra crítica, estaría construyendo la historia del sujeto cultural latinoamericano. Esta fijación con el lenguaje, la cultura y la ideología no es, por supuesto, excluyente de otras posibles claves; pero es la capacidad de legibilidad de nuestra crítica la que permite valorar su importancia como instrumento de lectura. Nuestra crítica confía en que 'sabe leer'; confía, por tanto, en que descubre condiciones y efectos de sentido porque nombra los aparatos discursivos: lenguaje, cultura e ideología (MARIACA ITURRI, 2007, pp. 10-11).

Por esos años, Carlos Rincón publica el artículo, "Entre la crisis y los cambios: un nuevo escenario" (1995), como introducción a trabajos que críticos y teóricos literarios de América Latina presentaron en el Coloquio Celebraciones y lecturas, la Crítica literaria en Latinoamérica, realizado en Berlín en 1991, y recogidos en la revista Nuevo Texto Crítico 14/15 (Julio 1994- junio 1995) de la Universidad de Stanford. En dicho texto, Rincón se refiere en un tono optimista al surgimiento de nuevos paradigmas críticos debido al redimensionamiento de lo literario con otros tipos de discursos y distintas formas de artefactos, sin olvidar el cambio de las condiciones epistemológicas en la producción del conocimiento en las décadas del 70 y $80 .{ }^{1}$

\footnotetext{
${ }^{1}$ En lo que respecta a la crisis de la crítica literaria son muchos los trabajos que la mencionan, incluso en momentos prematuros. En este sentido, es relevante el estado del arte expuesto en el número monográfico de Ideologies \& Literature ( $L \mathcal{E} L$ ) No. 16, Vol. IV de mayo-junio de 1983 del Journal of hispanic and luso-brazilian literatures, de la Universidad de Minnesota, Minneapolis E.U. Este monográfico reúne, bajo el título "Problemas
} 
No obstante, a pesar de la euforia que se puede colegir de lo anterior y más acorde con las posiciones del texto mencionado, en esta misma revista, el brasileño Silviano Santiago en el trabajo titulado "A crítica literária no jornal" manifiesta su preocupación en torno a las relaciones entre la producción literaria y el espacio de circulación de las ideas circunscrito a la prensa escrita no especializada. En este contexto, enfatiza su inquietud con relación a la posibilidad de que el escritor y el profesor universitario puedan participar de las grandes revistas y periódicos de circulación nacional e internacional. Esta propuesta, en términos de reacercamiento, pone sobre la mesa, de acuerdo con Santiago, el callejón sin salida en el que se encuentra tanto el género ensayo como la crítica literaria participante y, a partir de esto, menciona dos puntos a discutir: por una parte, el desfallecimiento del ensayo por el exceso de pedantismos y notas a pie de página; $y$, por otro, el abandono del ejercicio fundamentado y juicioso de la razón individual de la crítica. Estos aspectos a su vez remiten a algunas preguntas: la primera cuestiona, en el contexto actual de los medios masivos de comunicación, la posibilidad de re-escenificar un pacto anacrónico sostenido en textos escritos, más directamente, ¿cómo la participación de escritores y profesores en revistas y periódicos de gran circulación puede ponerse a favor del libro y la prensa escrita, enriqueciendo el debate de las ideas? La segunda pregunta indaga sobre la posibilidad de que el crítico literario ejerza un liderazgo intelectual deseable con el fin de enriquecer el diálogo entre especialistas (profesores) y no especialistas (público). Y por último, el autor se pregunta si el menoscabo del rigor científico, tanto en la ensayística como en la valoración de las obras, sería el costo a pagar en favor de la tradición literaria occidental.

En 1997, la argentina Beatriz Sarlo defiende la importancia de la crítica literaria en el contexto de los estudios culturales, enfatizando

para la crítica socio-histórica de la literatura: un estado de las artes", treinta trabajos resultantes del encuentro "El significado socio-político de la crítica actual (España, Portugal, Latinoamérica, Luso-África)”, llevado a cabo los días 9-10 de abril de 1982. En relación al tema aquí tratado vale resaltar el trabajo del chileno René Jara titulado "Crítica de una crisis: Los estudios literarios hispanoamericanos" (1983, pp. 330-352). En aras de la justicia, hay que reconocerle a René Jara una interpretación más crítica que optimista. Según él: "El énfasis en la concepción decimonónica que, con salvedades y excepciones, la crítica identifica en la narrativa del "boom", conduce a una desfiguración y a un desconocimiento de la complejidad de un sistema literario que tiene alto grado de heterogeneidad (...) si hay una crisis ésta se halla en los procedimientos de la crítica del "boom" (...)" (JARA, 1983, p. 351). 
la relevancia que tuvo el valor estético en un ejercicio crítico que, en las primeras décadas del siglo XX, fue decisivo en la construcción de una esfera pública moderna. ${ }^{2}$ También la franco-chilena Nelly Richard, en "Globalización académica, estudios culturales y crítica latinoamericana" (2001), si bien manifiesta la posibilidad de recuperar este lugar protagónico de la crítica, afirma la necesidad de desplazar la cuestión del valor literario "a otra formulación que abra los textos al análisis de las luchas entre los diferentes sistemas de valoración sociales a través de los cuales las hegemonías locales van modelando los significados y las representaciones de la literatura y de lo literario" (p. 193). Con esta finalidad, y en aras de establecer una propuesta viable, se aventura a formular al menos tres aspectos susceptibles de convertirse en guías de una posible redefinición de la función de la crítica literaria en América Latina. El primero apunta a la relevancia de la práctica al cuestionar la validez y la eficacia sociales de la crítica literaria en el ámbito de la sociedad mediática, caracterizada por la liviandad y estandarización del consumo simbólico; paso seguido, en relación con el segundo aspecto, el pragmático, indaga sobre las condiciones enunciativas y comunicativas a partir de las cuales la crítica intelectual podría desplegar sus estrategias de intervención social, en el caso de no resignarse al mundo de la exclusiva profesionalización académica; y, por último, el tercero, se refiere al valor de resistencia que presentan los giros metacríticos de una práctica del texto empeñada en indagar en los dobleces de la subjetividad y del pensamiento para, desde la escritura, oponerse al lugar común y a la transparencia mediática (RICHARD, 2000, p. 841). ${ }^{3}$

\footnotetext{
${ }^{2}$ El trabajo aludido se llama: "Los estudios culturales y la crítica literaria en la encrucijada valorativa” y fue publicado inicialmente en Chile, en la Revista de Crítica cultural No. 15 de 1997. Por otra parte es importante resaltar que la defensa de la crítica literaria en lo concerniente a la determinación del valor estético y la consiguiente adquisición de densidad política y ética no es una posición exclusiva de Beatriz Sarlo. En ese mismo año, Saúl Sosnowski, en el estudio introductorio, a la colección de Ayacucho Lectura crítica de la literatura americana. Inventarios, invenciones y revisiones, afirma: "Si bien es imprescindible asimilar los adelantos teóricos de las últimas décadas, no es menos crucial recuperar para la tarea crítica el enunciado de juicios de valor, pues estos permiten problematizar las relaciones de fuerza que afectan la producción cultural y hacer más efectivo el traslado del análisis literario a una mejor comprensión de la esfera pública”. (SOSNOWSKI, 1996, p. XXVII).

3 Se debe resaltar que gran parte de la argumentación, tanto de Sarlo como de Richard, se sustenta en los contextos posdictatoriales del Cono sur; no obstante, encontramos que, si bien dicha especificación es relevante, gran parte de los problemas y los argumentos planteados pueden ser aplicados al grueso de América Latina
} 


\section{EL PAPEL DEL CRÍTICO LITERARIO COMO INTELECTUAL}

La crisis de la crítica literaria ha tenido como atenuante - o su consecuencia - la desaparición del crítico literario en cuanto intelectual que interviene en el ámbito público. Esto, según algunos estudios, parece ser el resultado de la despolitización y la desideologización de la sociedad corroboradas en el contexto de la comercialización de los bienes culturales, el reino de la cultura del entretenimiento y la descentralización del canon erudito de la "ciudad letrada" (Cf. RICHARD, 2000, p. 842). Así las cosas, el cultivo privilegiado del ensayo en la crítica literaria y, en consecuencia, el predominio de la subjetividad en la interpretación, junto con la necesaria inclusión del interlocutor como norma predominante del género, podría constituirlo en una modalidad discursiva propicia para la recuperación de un fundamento político en una práctica discursiva que aspire a intervenir en el debate público.

Para tal efecto, el presente trabajo se propone resaltar el papel de la crítica literaria que, expresada a través del ensayo, pone en juego estrategias de intervención político-intelectuales durante las décadas del 40 y 50 del siglo XX. Tal como ha sido registrado por la ciencia política, la crítica de la cultura y los historiadores de la literatura, los rasgos enunciativos y comunicativos del ensayo le permitieron a la crítica propiciar y afrontar polémicas de carácter estético, político e ideológico en el continente, teniendo como consecuencia el hecho de que en "el arte y la literatura se aprendiera a re-politizar el gesto de la crítica desde los bordes cruzados de lo estético y lo ideológico" (Cf. RICHARD 200o, p. 847).4 En definitiva, se pretende poner en consideración una serie de reflexiones resultantes de la lectura de algunos ensayos del colombiano Hernando Téllez Sierra (1908-1966) publicados en diferentes épocas en torno al comentario de actualidades, políticas culturales y textos literarios. Asimismo, a partir de la identificación de un conjunto de rasgos y estrategias discursivas, la finalidad de esta lectura será reflexionar sobre parámetros concernientes

\footnotetext{
${ }_{4}^{4}$ Con esta afirmación se quiere resaltar, además de cierto inconformismo por parte de los críticos literarios del continente, las incontables polémicas generadas dentro de un país o entre países en torno a ideologías políticas, credos estéticos, posturas éticas a lo largo de la historia. A modo de ejemplo, podemos mencionar la emblemática polémica sostenida entre José Santos Chocano y José de Vasconcelos que unió a los dos extremos geográficos del continente durante las décadas del 20. A modo de información confrontar el folleto impreso en Madrid titulado: El poeta D. José Santos Chocano Contesta a Don José de Vasconcelos, editado por Calpe en 1925.
} 
a la intervención de la crítica no sólo en el ámbito estético y cultural, sino también en la esfera pública, lo que, en últimas, configuran al autor como intelectual.

En principio es relevante para este trabajo efectuar, muy someramente, una composición del lugar en el que vivió y ejerció su oficio el ensayista, periodista y escritor Hernando Téllez Sierra. De acuerdo con uno de sus mejores amigos, el expresidente de Colombia, Alberto Lleras Camargo, Téllez Sierra fue: "Un producto de la clase media en donde florece la inteligencia colombiana y se malbarata con más ligereza" (LLERAS CAMARGO, 1967, p. 15). Equiparado por su sentido crítico con Baldomero Sanín Cano, ${ }^{5}$ los inicios de Téllez Sierra en la escritura se dieron como asistente de Germán Arciniegas en la revista Universidad en la que participaron intelectuales hispanoamericanos como José de Vasconcelos y Juan José Tablada (RIVAS GAMBOA, 2001,p. 12). ${ }^{6}$ Esta revista se convertiría en la plataforma de la generación de poetas denominada Los Nuevos (1925), movimiento intelectual y literario, renovador del lenguaje poético, político y crítico al que pertenecieron intelectuales y escritores de la talla de Jorge Zalamea, Luis Vidales, José Artel y León de Greiff.

En medio del más retrógrado conservadurismo que llegaría a simpatizar con el fascismo, Téllez Sierra como casi todos los intelectuales llamados "disidentes" desde el Modernismo, se vería obligado a una férrea oposición en contra de las políticas partidistas y culturales del tradicionalismo ultramontano que, paradójicamente, simpatizaría con el ordenamiento económico del capitalismo internacional de finales del siglo XIX y principios del XX. En ese contexto, de acuerdo con Miguel Ángel Urrego (2002, p.8o), el ejercicio intelectual y el camino de la creación suponían enfrentar el modelo neoclásico e hispanófilo impuesto por la Regeneración e implicaba la disidencia estética y política. ${ }^{7}$

\footnotetext{
${ }^{5}$ Baldomero Sanín Cano es considerado el primer crítico literario moderno en Colombia. Ampliamente conocido en Hispanoamérica.

${ }^{6}$ Germán Arciniegas: periodista, novelista y crítico literario liberal de pensamiento progresista autor de innumerables libros sobra América Latina, promotor cultural, fundador y director de revistas literarias y ministro de Educación de Alfonso López Pumarejo presidente progresista y reformador (1934-1938 y 1942-1945)

7 En la historiografía colombiana, se denomina "Regeneración” (1886-1930) al movimiento político e ideológico que marcó el fin de la república federal del liberalismo radical de carácter secular, positivista y benthamista.
} 
Formado en esta atmósfera política e ideológicamente confesional, Téllez Sierra hizo parte del grupo de intelectuales simpatizantes con las ideas del liberalismo que, desde finales del siglo XIX, bajo la influencia del político liberal Rafael Uribe Uribe, daría un giro al ideario socialista. Dichas ideas fueron ahogadas por la represión conservadora que, temerosa del socialismo e incluso de los conatos anarquistas, reaccionaría con violencia desmedida ante cualquier signo de protesta popular y/o sindical. Es el caso de la virulencia con la que fue aplastado el levantamiento de un puñado de trabajadores colombianos de la multinacional estadounidense Unit Fruit Company, en Ciénaga (Magdalena), cuyo desenlace fue la desafortunada Masacre de las Bananeras (1928). Para destacar la presencia de ese ideario progresista en esa época, Maryluz Vallejo Mejía subraya la abundancia de periódicos a lo largo y ancho de todo el país y resalta, al menos, seis de renombre que circularon en Bogotá durante la segunda década del siglo XX: El Tiempo, El Espectador, El Diario Nacional, El Nuevo Tiempo, La República y La Crónica. Esto sin contar los periódicos de otras capitales como Medellín, Cali, Bucaramanga, etc. ${ }^{8}$

Como periodista bogotano, Téllez Sierra trabajó en El Tiempo ${ }^{9}$ $\mathrm{y}$, posteriormente, en proyectos intelectuales y políticos de la más diversa índole como la revista semanal Sábado (en la década del 40) y la emblemática revista Mito cuya duración abarcó desde 1955 hasta 1962 (VALLEJO MEJÍA, 2006, p. 344). A lo anterior habría que agregarle,

\footnotetext{
${ }^{8}$ Los cambios efectuados desde la tercera década del siglo XX, en el ámbito político y cultural colombiano, se explican por la aparición de una nueva generación de políticos entre los que resaltan: el presidente liberal Alfonso López Pumarejo y Jorge Eliécer Gaitán (primero socialista y posteriormente liberal) cuyo asesinato catalizaría el enfrentamiento bipartidista denominado periodo de la violencia colombiana que se ubica entre 1948 y 1958, pero cuyos antecedentes vienen desde principios del siglo XX. El ingreso de Gaitán a las filas del liberalismo se explica por el destierro y el encarcelamiento de los militantes de izquierda, tales como el editor Ignacio Torres Giraldo y María Cano, fundadores del partido socialista, con el consiguiente alistamiento de sus correligionarios a la filas del liberalismo. De acuerdo con Miguel Ángel Urrego el movimiento ideológico de izquierda fue de carácter continental. Afirma el historiador: "Asimismo, se produjeron cambios políticos en el ámbito continental que expresaban el ascenso del populismo y del nacionalismo - en México, Lázaro Cárdenas; en Perú Víctor Raúl Haya de la Torre; en Brasil, Getulio Vargas; en Puerto Rico, Pedro Albizu Campos, etc.-, tales movimientos exigieron de los intelectuales proyectos políticos, creación de referentes simbólicos y un mayor compromiso político con los partidos y el Estado" (URREGO, 2002, p. 86).

${ }_{9}$ De ideología liberal, este periódico haría una de las más efectivas oposiciones al dictador militar Gustavo Rojas Pinilla en 1958.
} 
además de ciertos coqueteos con la política, su papel en empresas culturales tales como la administración, junto a Roberto García-Peña y Jaime Barrera Parra, de las Ediciones Colombia fundada por Germán Arciniegas en la década del veinte (p. 350). Estas referencias, como señala Vallejo Mejía, resaltan el ejercicio del magisterio de Hernando Téllez, entre otros intelectuales, durante las décadas del 40 y 50 a través del calibramiento y jerarquización de las letras nacionales, lo que permite corroborar la importancia de la crítica literaria en la generación de la opinión pública, tal como lo planteara J. Habermas, al menos en las primeras décadas del siglo XX.

De acuerdo con el filósofo alemán, la opinión pública es el resultado de la progresiva autonomización de ciertos sectores de la sociedad burguesa en el siglo XVIII, en especial, del comentario literario que, posteriormente, daría origen a la crítica literaria como expresión de una práctica de carácter público que se sustentaría en el proceso de racionalización de Occidente. Al igual que en Europa, en América Latina, la conformación de la opinión pública es el resultado de la aparición de tertulias y grupos de lecturas, tendientes a la masificación del producto literario y, por supuesto, dependiente de los procesos de alfabetización. En un principio, un pequeño grupo de letrados se ocupó de la generación de la opinión pública y como se sabe, en el contexto de un régimen monárquico autoritario, no fue menos decisivo en América Latina que en Europa. Posteriormente, en el republicanismo, ese grupo tendría como labor la conformación de una esfera pública caracterizada por la defensa de raíces eminentemente partidistas que tuviera poder sobre las decisiones del Estado. Esta situación no tendría cambios muy notorios, en lo relacionado con sus efectos, durante el periodo en que Téllez Sierra ejerció como periodista y crítico literario.

En la actualidad se ha cuestionado que la teoría habermasiana explique el origen de la esfera pública y la opinión como resultado de la aplicación de la racionalidad en las discusiones sostenidas por individuos de diversos orígenes sociales y económicos en torno a las políticas públicas, decisiones de los gobernantes y comentarios literarios en las tertulias y cafés de Londres durante el siglo XVIII, pero lo cierto es que gran parte de sus argumentos parecen sobrevivir a dichos cuestionamientos. Aunque no estemos de acuerdo en que la racionalidad burguesa sea la única responsable de la aparición de la opinión pública y se pueda prescindir de la influencia de otros ámbitos y sectores sociales, no deja 
de ser relevante para nuestro tema reconocer la importancia de un cierto resurgimiento del ámbito de la subjetividad como lo opuesto no a la esfera política, sino a la esfera social. Desde esta perspectiva, lo subjetivo y lo social se constituyen en los dos modos de la existencia humana, lo que en palabras de Hannah Arendt, se puede corroborar con el surgimiento de la novela durante el siglo XVIII y su posterior desarrollo de finales del siglo XIX (ARENDT, 1996, pp. 49-50). Con estas observaciones se estaría dirigiendo la atención a la existencia no de una, sino de varias esferas públicas; al menos una central (mayoritaria) y otras periféricas (o minoritarias). En términos generales, la primera tiende al consenso y a respaldar las instituciones de lo político; las segundas, constituidas por colectivos y comunidades de la sociedad civil, representan la política que busca desafiar a la esfera central. ${ }^{10}$

\section{ESTRATEGIAS COMUNICATIVAS Y ENUNCIATIVAS}

Hernando Téllez Sierra fue autor de traducciones, de una colección de cuentos y de siete libros de ensayos, entre los que se pueden mencionar Inquietud del mundo (1943), Bagatela (1946), Diario (1946), Literatura

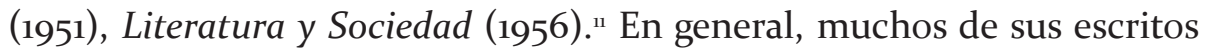
fueron inicialmente publicados en diarios de circulación nacional o en revistas y, posteriormente, pasaron a ser parte de algunas de las colecciones mencionadas. Es decir, estaban dirigidos a un público mayoritario y de esto da cuenta su escritura. Así lo expresa David Jiménez:

La obra de Téllez da la impresión por su tono, de ser el resultado de un diálogo interior entre los ecos de sus lecturas y los ecos de sus conversaciones mundanas. Hay mucho en ella de sabiduría convencional, adquirida en la frecuentación ordinaria con hombres de empresa, políticos y diplomáticos (...) Muchos ensayos de Téllez están construidos con el recurso -tan socorrido en él- de poner cierto tipo de argumentación en boca de un supuesto interlocutor

${ }^{10}$ En torno al concepto de la política en contraposición a lo político, Alain Badiou entiende a la primera como la refutación de lo segundo. Mientras la primera supone la necesidad práctica y empírica de orden; el segundo muestra que la regulación del conflicto es imposible. La primera es un principio socio-lógico y el segundo un principio onto-lógico (BADIOU, 2007, p.14).

"Además de las publicaciones de antologías y selección de prosas organizadas y prologadas por Juan Gustavo Cobo Borda bajo el auspicio del Instituto Popular de Cultura (Procultura) y la reimpresión de Bagatelas y Literatura y Sociedad por la Universidad de los Andes en 2014 y tres tomos de ensayos de crítica literaria con introducción, edición y notas de Carlos Rincón por el Instituto Caro y Cuervo (2017). 
que apela a los prejuicios y los tópicos del sentido común (JIMÉNEZ P., 1992, pp. 212-213).

Ese carácter conversacional de sus ensayos y la configuración de su interlocutor en el seno de los mismos le permite a Téllez intervenir en las polémicas del momento y, aprovechando su calidad de comentarista de la cultura colombiana y latinoamericana, proponer relecturas polémicas de clásicos literarios, cuestionar opiniones ampliamente aceptadas tales como la existencia de un pensamiento español, la relevancia del Quijote y de Cervantes en la cultura hispanoamericana, sin obviar su oposición a la inercia del lenguaje de las academias de las lenguas y apostar por el lenguaje popular, etc., incluso, afirmar la inexistencia tanto de una literatura como de una crítica literaria en América Latina. Muchas de estas posturas surgen de su férrea convicción política y otras del deseo de generar polémica y poner en entredicho lo que para muchos eran verdades de a puño.

En relación con lo anterior, vale resaltar el ensayo "Oro y cenizas castellanos", recogido en la colección titulada Literatura (1951), en donde Téllez hace acopio no solamente de su clara y amena escritura, junto a una capacidad descriptiva envidiable, sino de ese fino estilo irónico y cierto sentido del humor que le permitió lanzar las opiniones más mordaces. En efecto, refiriéndose al escritor colombiano Eduardo Caballero Calderón (1910-1993) y su obra Ancha es Castilla (1950), Téllez inicia este ensayo con una apreciación paradójica al afirmar que encuentra al mismo tiempo fascinante y mentiroso el libro de dicho autor. En medio de esta aparente contradicción, explica que el interés que la lectura de este libro le ha despertado se debe a la maestría e idoneidad con que afronta la lengua española que, aunque impregnada de "regia tradición", no cae en el preciosismo artificioso del tradicionalismo. Una vez sustentado el "enconado deleite" (p. 131) que justifica su interés por la obra de Caballero Calderón, Téllez prosigue con su distanciamiento crítico, pues, según él, “Ocurre que casi todas las tesis de Caballero Calderón sobre la historia, la política, el Estado, la sociedad, el hombre, la civilización, la cultura y, probablemente, sobre el peinado y los derechos de las mujeres, me producen la más amistosa rebelión intelectual" (p. 131). En este sentido, afirma nunca haberse puesto de acuerdo sobre nada con el autor y ni siquiera sobre España pues, en palabras de Téllez,

una de las tesis centrales de su extraordinario libro, la de que en el hombre español en quien advierte como fuerza esencial la irracionalidad, es, según 
dice, el más próximo de todos los hombres a las realidades concretas, resulta completamente indemostrable [...]"; sobre todo si se tiene en cuenta sugiere Téllez con ironía- que, en los más notables modelos españoles por antonomasia, Don Quijote, los místicos y los toreros, "[1]a noción de lo concreto y el poder de lo irracional son categorías antagónicas” (p. 131).

A modo de ejemplo, argumenta que "la fe de los toreros contra la muerte es maravillosamente irracional" pues, a pesar de lo concretas que pueden llegar a ser las astas del toro, "el diestro no se pone frente a ellos, sino llevado en vilo por un impulso irracional" (pp. 131-132). Esto significa, en palabras de Téllez Sierra, que "Si el hombre español hubiera hecho de la lógica y de lo concreto una dimensión de su vida, como el francés, no habría toreros en España" (p. 132). Además, y esta vez apuntando a lo relevante para el ensayista, "la interpretación de la historia de España, por una parte, y del carácter del español, por otro, conducen al autor de Ancha es Castilla" a formular un juicio sumario y desfavorable contra el proceso histórico contemporáneo; es decir, contrario al proceso de "colectivización", el español es "ferozmente individualista y, por ello, es el hombre total, el verdadero hombre, apunta Caballero" (p. 132). En este sentido, Caballero parece celebrar el hecho dequeel español sea el hombre "que está en pugna contra todo, contra el Estado, contra la norma, contra el convenio social" (p. 132). Para Téllez, esta apreciación de Caballero es reprochable en el sentido de que asigna "categoría de arquetipo humano al anarquista" (p. 133), dejando de lado el hecho indiscutible de que "toda civilización es compromiso", al igual que toda cultura. Desde el punto de vista de Téllez, esto es tan cierto que incluso en la historia española los acuerdos han posibilitado la realización de grandes hazañas y de más de una obra orientada al fortalecimiento de sus instituciones.

En definitiva, lo que le preocupa a Téllez de la postura de Caballero Calderón es el encomio a "la ley de la selva", lo que a la luz del presente de 1951 sería inaceptable, dado que la responsabilidad del intelectual, no puede negociarse ni relativizarse bajo los auspicios de ser una "teoría del artista", pues, aunque Caballero sea un artista, es evidente que "participa activa y belicosamente en la querella social y en la querella política de nuestra época" (p. 134) al punto de que sus posturas frente al presente y el pasado no puedan subestimarse. Desde la perspectiva de Téllez, se trata de un artista con una amplia audiencia a nivel nacional y es indiscutible que sus ideas deban ser analizadas y debatidas. Por ello, no puede pasarse por alto la peligrosa idea de que "el hombre se logra plenamente colocándose por encima de toda presión estatal, de todo 
compromiso social, de todo convenio político, de toda norma de relación que implique una comunidad o una solidaridad anónima [...] pues si bien se puede compartir la simpatía por el antitotalitarismo no se debe caer en el extremo opuesto de anarquismo social" (p. 134). A este respecto, fueron incontables las ocasiones en que Téllez se muestra renuente al colectivismo totalitarista. En especial, interesa resaltar su posición crítica con relación al fascismo en el contexto de la Segunda Guerra Mundial ("El arte dirigido" de 1943) y, posteriormente, tal como será comentado, al adoptar la postura del 'intelectual crítico', en relación con el capitalismo y el comunismo, como dos formas de colectivismo ("Notas sobre la conciencia burguesa", "Regalos", de 1956).

Sin hacer concesiones, Téllez no escatima la oportunidad de resaltar la nostalgia de feudalidad que se infiere de la admiración de Caballero por las iglesias, monasterios, palacios y torres de España. En este punto vale subrayar la resistencia de Téllez al legado español y su evidente favor a todo lo francés y, en cierta medida, a lo inglés, común a cierto sector intelectual del continente que, en su caso, dio origen a ensayos en contra de la tradición cultural y literaria ibérica que, no obstante, no deja de ser objeto de cierta admiración (p. 136).

En congruencia con lo anterior, me interesa resaltar la convicción de Téllez con respecto al papel del crítico literario como intelectual participante de la esfera pública en tanto generador de opinión que señala diferencias y contradicciones ocultas al ciudadano común. Es en este ámbito de estrategias argumentativas que debe ser pensada la colección de ensayos titulada Literatura y sociedad (1956), compuesta por ocho trabajos: "Notas sobre la conciencia burguesa", "El reino de lo absoluto", "Trópico", "El gran miedo", "Regalos", "Literatura y sociedad”, "Nadar contra la corriente", "Naturaleza viva” y "Escolios". Todos y cada uno ellos, sumándose en la configuración de un punto de partida que lo lleva, sin retorno, a la posición de intelectual autónomo "sumergido en la contienda". Sin duda, la sumatoria de estos ensayos hace gala de una concepción decimonónica del papel que debe cumplir todo crítico literario, en cuanto intelectual, y que se constituye a partir de la interpretación, no sólo de las obras literarias sino de los acontecimientos políticos, sociales e históricos.

La especificidad de esta concepción del trabajo intelectual, emanada de la interpretación de las obras literarias, de los hechos cotidianos, de los acontecimientos políticos e históricos, al adoptar la configuración del ensayo, en tanto "discurso situado", se configura a partir de la búsqueda 
de una verdad de la existencia particular en relación con su tiempo. Liliana Weinberg, al describir al ensayo como un texto de carácter "prometeico", coincide con la postura generalizada en América Latina en lo concerniente a la capacidad de intervención cultural y política de una crítica literaria de corte ensayístico. Para Weinberg, le corresponde al ensayo "[...] una forma enunciativa particular con fuertes marcas tensivas: un predicar sobre el mundo desde el punto de vista del autor que resulta al mismo tiempo el punto de partida de la reflexión, siempre referida a un presente del pensar y del decir [...]" (2007, p. 19). Sin dejar lugar a dudas, Weinberg reitera que "la inscripción del ensayo en el mundo [...] no sólo debe contemplarse como el vínculo mecánico entre texto, intertexto, contexto, etc., sino como el modo en que en el seno mismo del ensayo se representa, interpreta, despliega, reactualiza y re-simboliza en la relación con el mundo" (2006, p. 56). En mi opinión, Téllez, consecuente con su liberalismo radical, apuesta a la importancia de la racionalidad y, en consecuencia, al papel que debe cumplir el intelectual al aventurarse en explicaciones e interpretaciones en torno a las cosas del mundo. Un hombre de ideas del lado de aquellas voces del mundo más libres y nunca articuladas por los discursos hegemónicos o el sentido común.

Es el caso del razonamiento que Téllez despliega sobre la miseria y los mendigos en el ensayo titulado "Naturaleza viva" (1957). En este texto descarnado e irónico, adopta un tono burlesco para referirse a los sentimientos pequeños burgueses con respecto a la navidad. Tras un breve respiro de alegría, "temporada de los saludos y de los buenos deseos", “del sentimentalismo doméstico" (p.89), nos dice el autor, de repente irrumpe la presencia inoportuna de los mendigos, su 'insolencia' al pretender participar de la fiesta exhibiendo sin recato sus miserias. Esa "soberbia impertinencia de los mendigos" irrumpe en medio del orden burgués que, al igual que cualquier otro orden político, económico o religioso, no ha "podido digerirlos, asimilarlos, disimularlos o extirparlos" (p. 91). "Invencibles, irreductibles, inconquistables" (p. 92), son despreciados por la sociedad pues son el resultado de su inequidad. En opinión del ensayista, parece no haber existido tiempo, ciudad o sociedad que no los haya poseído y no los posea y, por ello, sería posible aventurar una tipificación. A modo de ejemplo, propone Téllez, mientras los mendigos neoyorquinos parecen confíar en el milagro de la Cenicienta y los napolitanos se aparecen desdeñosos y ofensivos, los mendigos bogotanos 
aparentan ser: "dueños y señores de su destino y del oficio que ese destino comporta y que la organización social les depara” (p.96).

Amparándose en la postura del intelectual desmitificador de la sociedad burguesa occidental, Téllez, en simetría con el tono mordaz, provoca en el lector una identificación que le avergüenza. La mendicidad -nos dice- "Es una categoría de la podredumbre y del desamparo sociales, señalada apenas como una excrecencia natural que la sociedad acepta en compensación de un determinado orden, de una determinada jerarquía de valores, de un sistema determinado" (p. 91).

En cada uno de los ensayos de Literatura y Sociedad se hace evidente, sin concesiones, el desafío del intelectual a la moral burguesa. Un intelectual que ha decidido no seguirle el juego a una sociedad que le ha impuesto históricamente el papel de cómplice. Este es el sentido de "Notas sobre la conciencia burguesa" (1957), el primer ensayo de la colección, en que Téllez emprende una comparación entre el régimen capitalista y el sistema soviético, reproduciendo la opinión que afirma que "el desarrollo capitalista, en los Estados Unidos, no genera ninguna forma social o política del colectivismo” (p.9). Sin embargo, señala el autor, no es necesario hacer un gran esfuerzo para descubrir "larvado o explícito" el progreso del colectivismo sin ningún tipo de resistencias subjetivas o intelectuales (pp. 9-10). En Estados Unidos el colectivismo de esencia burguesa tendría despejado el horizonte. Por otra parte, en lo que concierne a la Unión Soviética, la colectivización sería el resultado de la presión artificial del Estado "empeñado en crear la condiciones objetivas y subjetivas indispensables para el cumplimiento inexorable del proceso" (p. 11).

Este ensayo, dividido en 14 partes, siendo la comentada arriba la primera y la más extensa, revisa los aspectos relevantes que sustentan el ordenamiento burgués; el primer aspecto se ocupa de la posibilidad del enriquecimiento ilimitado y el prestigio del que goza quien lo consiga; el siguiente acápite alude al mito de la propiedad privada como parte del instinto del hombre; el tercero, a la aversión a la sexualidad y la demonización de los autores que la afrontan en sus obras, tales como Flaubert, D.H. Lawrence, Mauriac, Montherland. Paso seguido el ensayista se refiere a la capacidad de "resistir y disimular la avasalladora corriente del tedio" que acompaña la vida cotidiana entre las fiestas y los duelos de familia (p. 17). En relación con el arte y la corroboración de la moral burguesa, sostiene que la pintura abstracta llega a ofender 
su amor a los desnudos realistas. Por su parte, los escritores burgueses, entre los cuales Téllez se incluye, serían incapaces de asumir los riesgos a los que se hacen acreedores a partir de su crítica a la sociedad burguesa. En consecuencia, dice el autor "[...] preferimos aplazar indefinidamente esos riesgos, y continuar beneficiándonos de todas las ventajas del sistema que nos permite usufructuar la injusticia y aparecer de personeros de la justicia” (p. 19). Continuando con la enumeración y con cierto sarcasmo, el ensayista señala que la mujer pequeño-burguesa, "fortaleza de moralidad", se opone a la de la gran burguesía en el sentido en que "a la primera le interesa que un hombre crea en su pudor" (p.2o) y, a la segunda, "que el público se entere de que ella cree en el suyo” (p.20). Un acápite tras otro tiene como objeto revelar la doble moral y la hipocresía del burgués (el arribismo, la negación de la crisis de la familia, el falso dolor por la muerte de los demás y los funerales como ocasión para exhibir "la excelencia de sus sentimientos").

Más allá del juicio crítico que el autor lanza sobre el orden social de su tiempo, los textos referidos permiten identificar lo que Weinberg denomina el despliegue interpretativo en el presente. A propósito, afirma la autora: "El ensayo se da en el presente no sólo porque surge ligado a la inminencia de una situación vivida, sino también porque trata de dejar inscrito en el papel el carácter perentorio, activo, eléctrico, de la indagación del sentido, mostrarlo en su propia dinámica y participarlo" (2006, p. 63).

Por último, me interesa resaltar la calidad de sus escritos de ficción y su lucidez como crítico literario, dos cualidades íntimamente relacionadas en el caso de Téllez. Si bien es un hecho que, en su colección de cuentos Cenizas al viento y otros relatos (1950), logró dar un tratamiento estético inusitado al tema de la violencia colombiana al centrarse en las víctimas y así superar el carácter partidista de las novelas de la violencia escritas en estos mismos años, ${ }^{12}$ también lo es, el que en cada una de las reseñas de obras literarias contemporáneas, opte por el futuro de una literatura cuyo tratamiento temático y ficcional parece coincidir con el que él efectuó en

\footnotetext{
${ }^{12}$ Nueve años después de la publicación de este libro de cuentos, el joven Gabriel García Márquez publicaría su ensayo programático "Dos o tres cosas sobre la novela de la violencia" (1959) en donde resaltaría la importancia de la estética existencialista de la vertiente camusiana y las técnicas narrativas de Hemingway a través de las cuales podrían superarse las limitaciones de la literatura de la violencia carente de elaboración estética. Es muy posible que García Márquez aluda a Téllez pero por el lado de lo estético y no de las sugerencias técnicas.
} 
sus cuentos, aunque por lecturas y tradiciones diversas. Precisamente, debido al reconocimiento de esta distancia generacional, Téllez logra sostener una posición autónoma distante de cualquier dogmatismo y fundada en un sentido crítico no muy común en su generación y su tiempo. Es así como en 1964 no vacila en afirmar, en la reseña "Gabriel García Márquez: «La mala hora»", que a su autor “[...] le falta profundidad, espesor, cierta trascendencia de los caracteres, cierto relieve más hondo de los personajes, una complicidad, una identificación más visceral e irrevocable del creador con sus criaturas" (1979, p. 629), tal como lo reconoce la crítica actualmente, en lo que respecta a sus dos primera novelas. ${ }^{13}$

Si bien no le es posible eludir su formación liberal y decimonónica y se declare partidario de la literatura francesa e inglesa, en cada uno de sus juicios estéticos, Téllez reconoce el protagonismo que ha ido adquiriendo la literatura estadounidense en la década del 50. De ahí que afirme a propósito de La hojarasca, un tanto aturdido ante cierta incompresión del objetivismo narrativo:

[...] a diferencia de lo que acontece en el experimento proustiano, el creador de La hojarasca no pretende asumir sino una responsabilidad impersonal, casi diríamos técnica, casi diríamos administrativa, para suministrar y limitar, a cada una de sus criaturas, la correspondiente zona de acción, la correspondiente zona de autonomía, la correspondiente porción de libertad. El autor no está incorporado a la peripecia, ni al tema. No está sumergido en la acción. No es el centro de resonancia, ni el eje vital en torno del cual y en función del cual viven los personajes. Es apenas la criba que selecciona, clasifica y ordena (TELLEZ, 1995, p. 321).

\section{EL INTELECTUAL DE LA LITERATURA}

Al iniciar este texto mencioné como uno de los aspectos más relevantes en la actual crisis de la crítica literaria latinoamericana la relación polémica y desigual entre "saberes académicos, texto crítico y estrategias

\footnotetext{
13 Téllez afirma: "García Márquez está punto de llegar a esta situación, pero algo lo detiene todavía. ¿Su virtuosismo periodístico? ¿El brillo de su ingenio, de su gracia, de su don literario, que le permite jugar el juego verbal admirable, pero que parece distraerlo de lo que pudiera ser la esencia radical de sus creaciones? [...] Lo que no resulta temerario, en este caso, es predecir la riqueza de las próximas cosechas que este novelista puede darnos. Pocas veces es tan clara, tan perentoria, tan indiscutible, una vocación de escritor, y tan espléndido el instrumento verbal y la inteligencia y la gracia para manejarlo" (1979, pp. 629-630).
} 
de intervención político-intelectuales" (RICHARD, 2001, p. 841). En este punto parece haber unanimidad en el campo intelectual y, en especial, en los estudios literarios. En general, las respuestas que el conjunto de especialistas han dado a la crisis tienen en común recomendar el cultivo del ensayo, pues, como explica Weinberg:

El ensayo hace siempre ostensible la existencia de una perspectiva sobre el mundo que habrá de interpretar. El ensayo es un viaje intelectual por un mundo de significados y valores cuyo punto de partida es decisivo en cuanto a partir de él se sientan las bases del texto así como de su puesta en diálogo y contexto. El ensayo es un diálogo intelectual sobre el mundo cuya interpretación se va desplegando a través del texto (WEINBERG, 2007, p. 22).

En este sentido, sería decisivo re-politizar el gesto de la crítica orientándolo a la re-configuración de la tradición, a partir de la interpretación textual en defensa de la cultura, tal como lo sustenta Hannah Arendt en relación con la sociedad moderna y que, a la postre, no es más que el reconocimiento de múltiples esferas públicas en las que es posible identificar orientaciones mayoritarias y periféricas. ${ }^{14}$ Desde esta perspectiva, es precisamente a partir de la exploración del ensayo como género discursivo que la crítica literaria logró ocupar un lugar en el espacio intelectual en las décadas del 40 y 50.

Así las cosas, tal vez una de las estrategias discursivas más relevantes del ensayo sea esa inclinación a insertar a su lector en una reflexión de carácter literario, filosófica o política haciendo acopio del procedimiento fenomenológico, es decir, interrogándose sobre su propio acto de escritura desde el presente. En suma, dicha estrategia tiene como efecto la tensión resultante de la inscripción al ámbito enunciativo y la inserción en un horizote de sentido que, en definitiva, recuerda lo planteado en el ensayo "La brecha entre el pasado y el futuro" (1954) de Hannah Arendt.

14 De acuerdo con Peter Dahlgren (2012), a partir de su concepto de "ciudadanía mediatizada" y en relación a la esfera pública digital, es relevante establecer, al menos tres diferencias entre la Opinión Pública Central y la Opinión Pública Periférica. En términos de estructura, en relación con la primera, es posible identificar límites, regulación y control en lo concerniente a lo jurídico-político y lo económico; por el contrario en la Opinión Pública Periférica se aúnan la autogestión, la coparticipación y prácticas colaborativas y de intercambio; con respecto a la representación, la Opinión Pública Periférica presenta mayor pluralismo de voces, tendencias ideológicas y diversidad temáticas; por último, en relación con la interacción de los públicos proactivos de la Opinión Pública Periférica, inmersos en procesos de deliberación entre sí, frente a las audiencias reactivas de la Opinión Pública Central, cuya participación tiende a articularse al lucro corporativo, al simulacro o al fraude (SAMPEDRO-RESINA, 2010, pp. 151-152). 
De acuerdo con ella, el presente (tiempo del ensayo) se constituye en el "intervalo" entre el pasado y el futuro. El tiempo no es un continuo ininterrumpido, "es el punto dónde 〈él〉" [el enunciador del ensayo] se yergue, $\mathrm{y}$ 〈su〉 punto de mira no es el presente, sino más bien una brecha en el tiempo al que 〈su〉 lucha constante, 〈su〉 definición de una postura frente al pasado y al futuro otorga existencia (1996, p. 16).

Tanto el pasado como el futuro no son una carga sino expresiones de una fuerza. Este es el caso de la apuesta que Hernando Téllez realiza en lo concerniente a su lugar en un presente en el que los totalitarismos han cooptado a los intelectuales y en el que se debe redefinir, sino recuperar, el papel del intelectual. Así lo presenta en el ensayo "Escolio".

Ligado a la experiencia de la confrontación bipartidista, el caos político y social que hundió a Colombia en una oscura contienda política, Téllez denuncia "en presente" el rol de heraldos desempeñado por los intelectuales, juglares, propagandistas del poder, en un acto de contrición. Se afilia así a la tradición ensayística de occidente y, en especial de América Latina, al revelar la amenaza del presente: el intelectual corre el riesgo de desaparecer y exhibir una inoperancia en el contexto mundial de los totalitarismos. En esta brecha, el ensayista retomará el “yo acuso" de Émile Zola ante el caso Dreyffus y, tal como lo haría gran parte de sus compañeros ideológicamente afines, con el objeto de resituar al intelectual, convertirá en imperativo categórico la siguiente afirmación de Julian Benda: “[...] me parece importante que existan hombres, aun cuando se les zahiera, que guíen a sus semejantes a otras religiones que no sean las de lo temporal. Pero, los que sobrellevan la carga de esa tarea, y yo los llamo "clérigos", no sólo no la afrontan, sino que cumplen la tarea contraria” (TÉLLEZ, 1951, p. 9).

En este sentido, "Escolio" tiene como objetivo cerrar el conjunto de reflexiones en torno de su tiempo, el arte y el artista. No obstante, son los dos ensayos que lo preceden, "Literatura y sociedad" y "Nadar contra la corriente”, los que preparan esa reflexión definitiva. En relación con "Literatura y sociedad", homónimo del libro, su discurrir gira en torno a la defensa de la autonomía del artista y la consiguiente superación del compromiso social como imperativo categórico. Sobre este polémico tema afirma:

La literatura, como el arte todo, contribuye al quehacer histórico, al quehacer social, pero implícitamente, es decir extraprograma, extrajuicio, de manera autónoma y no subordinada. De ahí que los frutos "culturales" de organismos 
internacionales, empeñados en hacer del arte un vehículo de redención para los pueblos, sean tan débiles y frustráneos. El arte no es asimilable a la filantropía, ni a los credos políticos (TÉLLEZ, 1957, pp. 75-76).

"Nadar contra la corriente" también es una meditación en torno al arte, el artista y su autenticidad, representado con la imagen "nadar contra corriente". Con este recurso, el ensayista alude al artista como intelectual, debatiéndose entre la desesperación y la contrariedad. Para Téllez, el verdadero artista es un náufrago que pone en duda "la realidad artística anterior y establecida" (pp. 79-8o). Por ello no debe ceder ante la popularidad, ante el "intento de hacerlo coincidir con una necesidad extrapersonal, masiva, multitudinaria” (p. 84). Por ello,

\begin{abstract}
El artista, sería o es, ese empecinado nadador, ese náufrago potencial que resuelve dar pábulo a su desesperación y contrariar a sus semejantes, ofreciendo la realidad insólita, chocante que no corrobora sino que somete a la duda la realidad artística anterior y establecida [así] introduce una primera sospecha en el estatuto colectivo de la cultura. (TÉLLEZ, 1957, pp. 79-80)
\end{abstract}

Tras estas posturas que liberan tanto al arte como al artista de obligaciones ajenas a su libérrima tarea, termina su colección de ensayos con el "acto de contrición" en lo que concierne, a su ver, al papel del artistaintelectual como instrumento en el ejercicio del poder y, con esto, toma una posición que, en el contexto en el que es enunciada, aspira a ponerse "al lado de la verdad". De esta manera, aboga por la libertad y por el reclamo del lugar que, en calidad de artistas-intelectuales, históricamente les pertenece:

Anticipémonos a confesar que no nos resignamos a una fácil derrota ni a una fácil condena, porque fuimos y seremos imprescindibles aun para que el Líder, el Apóstol, el Juez o el Empresario puedan ejercer su magnánimo o su atroz mandato. Digamos sin humildad que ningún sistema prevalecerá contra nosotros aun sabiendo todo lo que fuimos como testimonio de grandeza y testimonio de servidumbre (1957, p. 104-105).

No obstante, Téllez se apresura a afirmar: "Nosotros agregamos la forma para escamotear la brutalidad" (1957, p. 105). y, paso seguido, propone el nuevo programa:

En adelante parece decirnos la historia, debemos contar con nosotros mismos, con nuestro rigor, nuestra decisión y nuestra verdad. Ya no podríamos, aun cuando quisiéramos, ahorrarnos el lodo, la sangre, la miseria, la crueldad y la injusticia. Estamos sumergidos en la contienda, hasta el cuello, nosotros que fuimos adorno, compensación y disimulo (p. 106). 
El nombre de este ensayo, "Escolio", supera la noción lexicográfica de comentario para adquirir una resonancia propia del ámbito intelectual colombiano. Me refiero a la producción filosófica en forma de aforismo de Nicolás Gómez Dávila (1913-1994) que, como afirma Efrén Giraldo, ha sido objeto de un reconocimiento tardío, aunque es posible encontrar comentarios de admiración por parte de Téllez, Ernesto Volkening y Rafael Gutiérrez Girardot. De hecho, en la década del 5o, Téllez publica un comentario en la revista Mito en el que afirma:

\begin{abstract}
Como en los casos clásicos de La Bruyére o La Rochefoucauld o de Joubert, el aforismo de Gómez Dávila es una especie de precipitado final que se resuelve, se expresa y sintetiza un largo proceso de meditación, y en que se cristaliza y codifica una vasta corriente de experiencia y sabiduría [...] Una dura punta de diamante. He ahí la definición perfecta y la calificación, no menos perfecta, de sus notas y para sus notas. Todo cuanto aparece explícito en ellas, en esa apretada estructura, se halla, sin embargo, como en la punta de diamante, subyacente, incorporado, tácito (1955, p. 209). ${ }^{15}$
\end{abstract}

Independientemente de las diversas apreciaciones que ha recibido la obra y la postura ideológica de Gómez Dávila como pensador conservador y reaccionario, en la historia intelectual colombiana, tal como lo afirma Giraldo, se le concede un no desdeñable reconocimiento en el campo de la filosofía (2014, p. 405). Es decir, lo que me interesa resaltar es la afiliación en torno al cultivo del ensayo tanto de Gómez Dávila como de Téllez, quienes desde posturas, en apariencia, antípodas - el primero, estilista y esteta más allá de la sistematicidad de su pensamiento, lo que Téllez supo reconocer tempranamente- y el segundo, cultivador de particularismos y de la observación de la vida cotidiana, coinciden en la importancia de la vinculación de la ética y la estética en la escritura. En definitiva, es posible encontrar en los autores concepciones del intelectual en razón de una forma discursiva que los aproxima y una práctica intelectual que los distancia.

Para terminar, no está de más recordar que he considerado relevante retroceder a uno de los momentos históricos más significativos de la crítica literaria, las décadas del 40 y 5o, e indagar, a la manera de una pequeña

\footnotetext{
${ }^{15}$ A modo de ejemplo, además del escolio que aparece como primer epígrafe de este trabajo, se pueden citar los siguientes aforismos de una selección hecha por la Revista Mito: "Ningún acto material basta para destruir una civilización. Las civilizaciones mueren de la indiferencia ante los valores específicos en que se fundan"; "El hombre no es el vehículo de las ideas, sino su ambigua y dura realidad"; "La sociedad del futuro: una esclavitud sin amos" (GÓMEZ DÁVILA, 1955, pp. 211-214).
} 
muestra, la actividad de Hernando Téllez Sierra. En razón de la aparición de un tipo de intelectual que se desempeña como crítico literario, considero pertinente la clasificación que presenta Gonzalo Aguilar en "Los intelectuales de la literatura: cambio social y narrativa de identidad" (2010). De acuerdo con el autor, al referirse al "intelectual de la literatura" no alude a aquellos intelectuales provenientes de la poesía o el ensayo literario de ideas o de la narrativa, sino a aquel que originariamente ha fungido como crítico literario y que, a raíz de esta actividad, se ha proyectado como figura pública (AGUILAR, 2010, p. 685).

En este ejercicio de la crítica, según Aguilar, es posible identificar dos momentos. El primero corresponde a aquellos personajes, tales como Émile Zola o José Martí, para quienes su actividad literaria e intelectual estaban íntimamente unidas. Ubicados a finales del siglo XIX hasta primera mitad del siglo XX, gran parte de ellos provenía de la poesía, ensayo y/o narrativa (2010, p. 685). El segundo momento, se inicia en las décadas del cuarenta y del cincuenta y su rasgo sintomático es el abandono de la "ensayística libérrima" con el objeto de ocuparse de la investigación "asidua y documentada”. Poseedores de una formación disciplinar en técnicas y metodologías para interpretar textos literarios y darles una significación social, cultural y eventualmente política, estos críticos literarios en cuanto intelectuales son el resultado de los procesos de consolidación y modernización, del crecimiento del mercado de bienes simbólicos, junto a los exitosos procesos de alfabetización y al aumento de la población lectora. Esta segunda generación, se caracteriza, además, por la continentalización del discurso crítico a partir de la Revolución cubana en 1959.

En general, el intelectual de la literatura nace cuando su labor, relacionada con la interpretación de textos literarios, se desplaza del aula al espacio público. El crítico ya no se restringe al claustro universitario sino que interpela a un público amplio y logra cuestionar ciertos lugares comunes del imaginario social y los poderes establecidos. En la medida en que la literatura se constituye en un espacio formador de ciudadanía y diatriba al estado de cosas, el crítico literario compite con los autores de obras literarias a quienes se les había atribuido dicha labor tradicionalmente. Es en este contexto que se hacen pertinentes las preguntas formuladas por Nelly Richard, sobre la liviandad y la estandarización de la sociedad mediática y su relación con la crítica; sobre las condiciones enunciativas y comunicativas mediante las cuales 
se hace posible la intervención social y, por último, sobre los valores de resistencia de una práctica metacrítica, en términos de subjetividad y pensamiento, en oposición al lugar común de la transparencia mediática (RICHARD, 2000, p. 841).

Si bien Aguilar toma como modelo de este tipo de intelectual a los críticos Antonio Candido, Ángel Rama y Antonio Cornejo Polar, creo que a Hernando Téllez Sierra, nacido en 1908 y fallecido en 1966, es posible pensarlo en la frontera entre la primera y segunda etapa. Es evidente que en su caso no se aplicaría de manera rigurosa este tipo de descripción, pues uno de sus rasgos más relevantes es, precisamente, haberse constituido como crítico literario haciendo acopio del cultivo del género ensayístico y haber hecho de las características de este género discursivo su mayor aliado en la participación y la generación de opinión pública, pues gran parte de su obra fue escrita para ser publicada en periódicos nacionales, lo cual no significa que, en cada uno de sus ensayos, su postura intelectual no esté respaldada por una formación teórica, estética y política. Es posible que la más grande conclusión que se puede extraer sea que en las dos primeras décadas del siglo XX, en América Latina, se precipitaron tal cantidad de cambios en los ámbitos académico, político y social que, con la diferencia de tan sólo diez años, se iniciaría un vertiginoso proceso de profesionalización de la crítica que desembocó en su aislamiento en las aulas universitarias.

No obstante, a la luz de los actuales acontecimientos y las profundas crisis en la que parece estar sumergida la crítica literaria ¿será políticamente relevante el esfuerzo diario del crítico literario por mantener una columna en los medios masivos de comunicación, digitales o impresos, al punto de considerarlos a la altura de las circunstancias mediáticas, sin que esto signifique convertirse en "adorno, compensación y disimulo"? (TÉLLEZ, 1956, p. 106).

\section{REFERENCIAS}

AGUILAR, Gonzalo. (2010). Los intelectuales de la literatura: cambio social y narrativas de identidad". In Historia de los intelectuales en América Latina II, Buenos Aires: Akal.

ARENDT, Hannah. (1954). Entre el pasado y el futuro. Ocho ejercicios sobre reflexión política. Barcelona: Ediciones Península, 1996.

BADIOU; Alain. (1990). ¿Se puede pensar la política? Buenos Aires: Nueva Visión, 2007. 
BOURDIEU, Pierre. (1984). La opinión pública no existe. In: Sociología y cultura. México D.F.: Editorial Grijalbo, 1990, pp. 239-250.

CANDIDO, Antonio. (1989). O ato crítico. In: A educação pela noite E outros ensaios. São Paulo: Editora Ática, pp. 122-137.

GIRALDO, Efrén. (2014). La poética del esbozo. Baldomero Sanín Cano, Hernando Téllez, Nicolás Gómez Dávila. Bogotá: Universidad de los Andes.

GÓMEZ DÁVILA, Nicolás. (1955). Escolios escogidos. In: Mito. Revista Bimestral de cultura. Año I, No.4, pp. 209-2018.

DALHGREN, Peter (2012). Mejorar la participación: la democracia y el cambiante entorno de la web, disponible en http://www.ciberdemocracia.net/victorsampedro/ articulos/ Acceso 12 feb. 2017.

JIMÉNEZ P., David.(1992). Historia de la crítica literaria en Colombia. Bogotá: Universidad Nacional de Colombia- Instituto Colombiano de Cultura, 1992.

LLERAS CAMARGO, Alberto. (1966). Prólogo. In: Confesión de parte (Literarias, sociales, notas). Bogotá: Talleres gráficos del Banco de la República, pp. 9-19.

MARICA ITURRI, Guillermo, (1993). El poder de la palabra. Ensayos sobre la modernidad de la crítica cultural hispanoamericana. Santiago: Tajamar Editores, 2007.

RICHARD, Nelly. (2001). Globalización académica, estudios culturales y crítica latinoamericana. In: Cultura, política y sociedad. Perspectivas latinoamericanas, Buenos Aires: CLACSO, pp. 185-199, 2001.

RICHARD, Nelly. (200o). Un debate literario sobre práctica intelectual y discurso crítico. In Revista Iberoamericana. Pittsburg: University of Pittsburg, Vol. LXVI, No. 193, pp. $841-850$.

RINCÓN, Carlos. (1995). Entre la crisis y los cambios: un nuevo escenario. In: Nuevo Texto Crítico. Stanford: University Stanford, Vol. VII, Nos. 14.15, pp. 5-10.

RIVAS GMABIOA, Ángela (2001). Un estudiante maestro. In Historia Crítica. Bogotá D.C.: Universidad de los Andes. No. 21, enero-junio, pp. 7-35.

SAMPEDRO Blanco, Víctor- RESINA DE LA FUENTE Jorge. (2010). Opinión pública y democracia deliberativa en la Sociedad Red. In: Ayer. Historia política y opinión pública. Revista de historia contemporánea. Madrid, Asociación de historia contemporánea- Marcial Pons, No. 8o, Vol 4, pp. 139-162.

SARLO, Beatriz. (1997). Los estudios culturales y la crítica literaria en la encrucijada valorativa. In: Sarlo, B.; Schwarz, R. y Kraniauskas, J. (eds.), Culturas híbridas-No simultaneidad-Modernidad periférica. Mapas culturales para la América Latina. 2000, pp. 231-240. 
SARLO, Beatriz. (1994). Intelectuales. In: Escenas de la vida posmoderna. Intelectuales, arte y videocultura en Argentina. Buenos Aires: Ariel, 1999, pp. 173-198.

SOSNOWSKI, Saúl. (1996). Cartografía y crítica de las letras hispanoamericanas. In: Lectura crítica de la literatura americana. Inventarios, invenciones y revisiones. Caracas: Biblioteca Ayacucho, pp. IX-XC.

TÉLLEZ S., Hernando. (1956). Literatura y sociedad, Bogotá: Ediciones Mito, 1957.

TÉLLEZ S., Hernando. (1995). Nadar contra la corriente. Escritos sobre literatura. Santafé de Bogotá D.C.: Editorial Ariel.

TÉLLEZ S., Hernando. (1979). Textos no recogidos en libro. T.II, (Editor) J.G. Cobo Borda. Bogotá: Instituto Colombiano de Cultura.

TÉLLEZ S., Hernando. (1955). (Atribuido). La obra de Nicolás Gómez Dávila. In: Mito. Revista Bimestral de cultura. Año I, No.4, pp. 209-2018.

TRABA, Marta (1969). Prólogo. In J.G. Cobo Borda (Editor) Hernando Téllez. Textos no recogidos en libro. Tomo II. Bogotá: Instituto Colombiano de Cultura, 1979, pp. 933941.

URREGO, Miguel Ángel. (2002). Intelectuales, estado y nación en Colombia. De la guerra de los Mil Días a la Constitución de 1991. Bogotá D.C.: Universidad Central -DIUCSiglo del Hombre Editores.

VALLEJO MEJÍA, Maryluz. (2006). A plomo herido. Crónica del periodismo en Colombia (1880-1980). Bogotá D.C.: Editorial Planeta.

WEINBERG, Liliana. (2014). Crítica literaria y trabajo intelectual. In: Utopías móviles, Nuevos caminos para la historia intelectual en América Latina. Bogotá D.C: Diente de León- Universidad de Antioquia, Facultad de Comunicaciones, pp. 90-116.

WEINBERG, Liliana. (2007). Pensar el ensayo. México: Siglo XXI.

WEINBERG, Liliana. (2001). El ensayo, entre el paraíso y el infierno. México, D.F.: FCEUNAM. 